\title{
What makes a successful undergraduate? The relationship between student characteristics, degree subject and academic success at university
}

British Educational Research Journal

Emma Smith and Patrick White

University of Leicester

es228@1e.ac.uk

\begin{abstract}
This paper contributes to the empirical evidence on participation and attainment in higher education by reviewing the patterns of entry and success of undergraduate students. It examines the characteristics of entrants to different subjects and considers the role that subject studied plays in determining the likelihood of graduating with a 'good' degree. The data used were drawn from the administrative records of over 38,000 UK-domiciled undergraduate students from one 'elite' British university. Despite considerable betweensubject variation in degree outcomes, multivariate analysis of the relationship between students' social and academic characteristics and achievement at university revealed that, once social background and prior attainment had been controlled for, the subject students studied added little explanatory power to models predicting final degree classifications. Differences in degree outcome were most strongly related to attainment on entry to higher education, sex and ethnicity. In contrast with attainment during the earlier phases of education, the relationship with occupational class was relatively weak. Disparities between the proportion of higher level classifications awarded in different subjects can be largely explained by the background characteristics of the students who choose (and are accepted) to study on these degrees. This finding has particular implications for policies aimed at increasing both the number and quality of STEM graduates in what is often argued to be a 'shortage' or 'priority' area.
\end{abstract}

Keywords: higher education; achievement; inequality; STEM. 


\section{Introduction}

Over the last fifty years Higher Education in the UK has moved from being an elite to a mass experience (Furlong and Cartmel 2009). In 1963 just 8.5\% of the British population went to university; by the start of the twenty-first century it was nearer to $40 \%$ (Chowdry et al. 2010). This expansion of the sector, coupled with the rising cost of tuition fees and an increasingly competitive graduate employment market, has implications for ensuring 'fair and equal' access to university as well as providing a challenge to Higher Education's purported status as 'an engine of economic growth and social justice' (Naylor and Smith 2004:416). The consequences of both increasing and widening participation in HE have led to concerns about whether the demand for graduates by employers can keep up with supply or, alternatively, if expansion will lead to large proportions of graduates finding themselves underemployed or unemployed (Green and Zhu 2010, Elias and Purcell 2013). In a more competitive job market the type and quality of graduates' degrees will be increasingly important for jobseekers and employers alike. This issue is particularly pertinent in areas when concerns have been raised by employers about the quality of graduates and their level of readiness for the workplace, as has happened most notably in Science, Technology, Engineering and Mathematics (STEM) occupational sectors (e.g. House of Lords 2012).

This paper considers the relationship between student characteristics and academic success for different university subjects. Because of the concerns raised both about the supply and quality of STEM graduates, particular attention is paid to these subjects. The research questions for this study were as follows:

1. How do the characteristics of undergraduate science students studying at one 'elite' British university compare with those who study other subjects?

2. What is the relationship between student characteristics and degree success?

3. To what extent is the subject students study related to their final degree outcome?

\section{Participation in Higher Education in the UK}

The recent rapid growth of Higher Education in the UK is reflected in a quadrupling of the number of candidates offered places to study at undergraduate level (Smith and Gorard 2011). But while going to university may have become part of the 'normal taken for granted 
experience of the middle classes' (Furlong and Cartmel 2009: 121), it is still the case that inequalities in student participation persist in high status subjects, particularly at 'elite'1 universities (e.g. OFFA 2010, Boliver 2013). A recent report from the Social Mobility and Child Poverty Commission (2013:2) censures these elite universities (and the Russell Group ${ }^{1}$ in particular) for not doing enough to widen access and promote social mobility:

This evidence shows that some of our leading universities in particular have a long way to go: they have become more, not less, socially unrepresentative over time. The proportion of students at these institutions from state schools and from disadvantaged backgrounds is lower than it was a decade ago. This is unacceptable and must change.

In recent years recruitment to UK universities has changed in several ways. The number of entrants from traditionally under-represented groups have increased and applicants who have the minimum required grades for entry to HE have usually been able to secure a place at an institution (Gorard et al. 2007). But there is also compelling evidence that many students from previously under-represented groups are less likely than more 'traditional' applicants to study at the 'elite' universities (Furlong and Cartmel 2009, Mangan et al., 2010).

The consequences of both increasing and widening participation in HE have led to concerns about whether the demand for graduates by employers can keep up with the supply and whether, as a result, large proportions of graduates will find themselves in non-graduate jobs (Dolton and Silles 2003, Elias and Purcell 2004). According to Chevalier (2000), having an over-educated graduate workforce may lead to a number of potential consequences: graduates being recruited to jobs that do not require graduate-level skills; and employers raising their entry-level qualification requirements. With increasing numbers of people entering $\mathrm{HE}$ it is unsurprising that attention has turned to the career destinations of recent graduates and that, in a competitive job market, performing well at university has become crucial for the successful transition into the labour market. Research by the Association of Graduate Recruiters shows that over three-quarters of graduate employers will only interview candidates who have at least an upper second class degree $(2: 1)^{2}$ (BBC 2010, The Guardian 2012, AGR 2012). Those who graduate with a lower second class degree (2:2) or below will also see some opportunities for postgraduate study closed to them; entry to many primary initial teacher education courses, for example, requires at least a 2:1. This has led Seaton 
(2011, n.p.) to conclude that 'life chances available to a student with a 2:1 and a student with a 2:2 are very different indeed'.

Previous work on the determinants of HE outcomes shows that degree performance is associated with characteristics such as ethnicity, age, gender and occupational background (e.g. Barrow et al 2009, Richardson and Woodley 2003, Ogg et al. 2009). There is also a large body of evidence that has identified a substantial relationship between pre-university attainment and the likelihood of doing well at university (e.g. McNabb et al 2002). Smith and Naylor (2001) estimate that a three grade rise in A-level outcomes (e.g. from BBB to AAA) is associated with around a 10 percentage point increase in the likelihood of graduating with a 'good' degree (2:1 or First). Although there is variation in the proportion of degree classifications between subjects, there is very little work examining the role that subject plays in determining differential degree outcomes (Woodfield and Earl-Novell 2006). What work that has been undertaken does suggest that STEM subjects, especially engineering and physical science disciplines, may be more likely than arts subjects to award a higher proportion of 'good' degrees (here characterised by the allocation of first class awards) (Richardson 2003, Woodfield and Earl-Novell, 2006). Research conducted at the University of Cambridge concluded that science students are over one-and-a-half times more likely to be awarded a First than their fellow arts students (Surtees et al., 2002). One explanation for such patterns is that science disciplines are more likely to adopt marking regimes based on right/wrong answers, resulting in a wider distribution of grades than arts subjects, where marking practices might rely more on subjective judgements (Woodfield and Earl-Novell 2006). As discussed below, concerns about the supply of highly qualified graduates to the STEM workforce are well-rehearsed (e.g. House of Lords 2012), and therefore any evidence of differential attainment at university between those who study arts and science subjects is of particular interest.

\section{Recruitment to STEM subjects in Higher Education}

In the context of an expanding HE sector and the frequent reiteration by government of the symbiosis between a buoyant HE system and the country's economic prosperity, one area that has been singled out for particular attention is recruitment to Science Technology Engineering and Mathematics (STEM) ${ }^{3}$ subjects (e.g. DfES 2006, BIS 2009). Many of these subjects occupy a privileged position in UK government HE policy. They have been given 
priority status as 'strategically important and vulnerable' subjects (HEFCE 2008) and, in the context of ongoing funding cuts to the HE sector in England, have been one of the key areas identified for 'enhanced support' by both the previous Labour government and the current Coalition administration (e.g. BIS 2009:45). They are also subjects that reportedly struggle to recruit the 'brightest and best' and attract a disproportionate number of students from a relatively narrow band of the social spectrum (Smith and Gorard 2011, Sutton Trust 2008).

An expanding Higher Education system means that more scientists are being trained than ever before. In 2009, almost 200,000 students began studying for full-time undergraduate degrees in science and science-related subjects, a number that has trebled since 1986 (Smith 2010). But despite this increase, inequalities in participation persist. While much of the literature in this field has focused on the experiences of female entrants (e.g. Ceci et al. 2009, Purcell et al. 2006), research also identifies barriers faced by students from other nontraditional backgrounds (e.g. Wynarczyk and Hale 2009, Reay et al., 2005). Solutions for improving recruitment to STEM subjects and careers have traditionally been sought through reform of science education in schools (Jenkins and Donnelly 2006). Much less attention has been paid to the undergraduate student experience and the trajectory that learners take into careers as professional scientists and technicians.

Although the primary goal of this paper is to examine relationships between subject studied, social background and degree outcome, the data also enabled a comparison of outcomes between STEM and non-STEM subjects, an aspect that is often absent from other accounts.

\section{Data}

The data used in this paper were drawn from individual student administrative records collected by one large British university. Data were available for the whole of the university student population but for the purpose of this paper were restricted to full-time homedomiciled undergraduate students who entered the university between 1998 and 2006. This corresponds to the majority of students graduating between 2001 and 2009. This group was selected in order to study students who have shared a relatively common pre-university experience and were likely to enter the labour market in the UK.

The final population comprised between 3,000 and 4,000 students in each cohort, giving a total of 38,236 students. Despite providing a rich source of high quality contextual data, as 
with all secondary (and particularly administrative) data sets, information was not available on all the variables that could plausibly be related to academic outcomes. For example, the data can tell us nothing about the many unobserved or unrecorded factors or events that will have occurred in these students' lives, as well as their levels of motivation and interest in their subject or the quality of teaching on their course (see for example Mellanby et al. 2013).

The outcome variable used in the multivariate analyses was the degree classification awarded to students upon graduation. As discussed earlier, opportunities for employment and further study are generally wider for graduates with a 2:1 or a First Class degree than for those with lower classifications, further detail is provided below. In addition to degree outcomes for different subjects, this study also examined the relationship between the social and academic characteristics of students and their degree success. The variables used in the analyses can be grouped into the following categories:

\section{Birth characteristics}

These variables include all those characteristics respondents could be considered to have from birth, including: sex; ethnic group; parental occupational class and age. Deciding how to best categorise ethnicity, occupational class and age was not straightforward. The large number of ethnic group categories can result in small cell sizes when the data are analysed, for example. So this process was informed by theoretical, practical and statistical considerations. The distribution of students' ages reflected the structure of common postcompulsory educational trajectories but also included substantial numbers of 'mature' entrants. Additionally, allocating HE students to an occupational group that depends on their family circumstances can be particularly problematic, especially for those who are of nontraditional age (Gorard 2008, Harrison and Hatt 2009). With this in mind, for the purpose of analysis a number of adjustments were made to the variables:

Ethnic group: Ethnic group was self-declared by the applicant and coded into 10 categories as specified by the University Central Admissions Authority (UCAS). For clarity only descriptive data relating to the largest ethnic groups are provided in this paper. In the multivariate analyses two different models are presented. The first, most parsimonious, model categorises students as either being from the majority ethnic group (white) or from the minority ethnic group (here labelled as 'non-white'); while the second presents the data for each ethnic group analysed separately (see Table 4 in the Appendix for further commentary). A detailed consideration of the participation and outcomes of students from ethnic minority, 
and indeed other social groups, is of key importance when researching equity issues in Higher Education. However, the main focus of this paper is on subject choice and therefore space does not allow us to provide a full discussion of all the findings to emerge from this study.

Occupational class: Data on occupational class were collected in four categories based on the SOC 2000 scale. For the purpose of multivariate analysis these were collapsed into two groups: Higher/Lower Professional and Intermediate/Routine occupations. This categorisation has been used in many previous analyses of class differences in higher education participation. As indicated above in the discussion on ethnic group data, there is a tension, when analysing large datasets, between providing the most parsimonious statistical model and sharing the outputs for all the variables that were available for analysis. We recognise this tension and have provided the full output from the multivariate analysis in Table 4 (see appendix), and the simpler, more parsimonious output in Table 3.

Age: Two categories were used: students aged 17-20 years on entry (traditional age) and those aged $21+$ (non-traditional age). This division reflects the distinction between students entering HE shortly after leaving school or college and those 'mature' entrants who participate later in life. In addition and following the discussion above, a more detailed analysis of the data broken down by age group is available in the appendix (note however that the relatively small size of some age groups can have a destabilising effect on the model).

\section{Geographical characteristics}

Geographical characteristics of the student population are important to consider when investigating participation and outcomes in HE. This is particularly relevant in terms of an institution having a representative mix of students from the local area and is a key element of this university's fair access agreement (Office for Fair Access 2014). The data used in this analysis are derived from the students' home postcode at the time they made their original application to the university. They enable the distance from each student's home address to the university campus to be calculated, in turn allowing them to be categorised as 'local' to the university (notionally residing less than $20 \mathrm{~km}$ from campus) or 'non local' (residing at a distance of greater than $20 \mathrm{~km}$ from campus). By combining this postcode data with HEFCE Participation of Local Areas (POLAR) maps it was also possible to classify students according to rates post-compulsory educational participation in their area of residence. Two 
of the POLAR indicators of participation were used in the analyses: the young participation rate; and the adult Higher Education engagement rate. The POLAR area classifications are presented as five ordered quintile groups (HEFCE 2012).

\section{$\underline{\text { Academic characteristics }}$}

These include the previous educational establishment that the student attended (four categories of data) and their entry qualifications (in terms of A-level grades). Students were separated into two groups according to their entry qualifications: those who entered with grades $\mathrm{ABB}$ or above and those whose grades were below $\mathrm{ABB}$. $\mathrm{ABB}+$ was chosen to differentiate students with the highest entry grades because at the time of writing it is the level the government adopts as part of its 'high grades' policy that allows universities and colleges to recruit unlimited numbers of students with the highest grades (HEFCE 2013).

\section{$\underline{\text { Subject studied }}$}

Analysis focused on the five main subject disciplines that were taught at this institution as well as the 15 largest recruiting individual subjects. The latter were defined as subjects that recruit more than 40 students into each cohort annually. In the logistic regression models the reference categories for subject groups and individual subjects were those subject areas that graduated the highest proportion of students with a 2:1 degree or higher (the 'arts, humanities and law' subject group and 'history' for individual subjects).

\section{Analysis}

As variation in the characteristics and outcomes of students across the nine cohorts was reasonably small (see Table 4 in appendix), data from all nine cohorts were combined for the main analysis. As the data used in the analyses represent the entire population of homedomiciled undergraduate students at this university, rather than any kind of random sample, inferential statistical tests were neither appropriate nor necessary (see Gorard 2003, 2010, 2014, White 2014, but see notes accompanying Table 4 in appendix).

Patterns in the data were first explored using univariate and bivariate techniques. These patterns are described before the results of the multivariate analyses are presented. Logistic regression analysis was then used to identify the social, economic and educational characteristics most strongly associated with achieving a 2:1 degree or higher in different subjects at the end of university. The outcome variable was dichotomous, with students 
divided into those who graduated with $2: 1$ or 1 st class degree and those who received a 2:2 or below. Across the cohort, $66 \%$ of students fell into the $2: 1 / 1^{\text {st }}$ category with $34 \%$ graduating with a $2: 2,3^{\text {rd }}$ or fail, a distribution of grades that reflects the pattern nationally (HESA 2014).

Variables were entered into the models in a series of 'blocks'. Only variables that improved the predictive power of the model were retained at this stage (but see the full model provided in Table 4). The first block contained information relating to the social and economic backgrounds of students and included variables relating to: sex, age, occupational class and ethnicity. These variables were all dichotomous. Students were divided according to whether they were: male or female; 'traditional age' or 'mature' entrants; from a professional or other occupational background; and whether they identified themselves as 'white' or as a member of a minority ethnic group.

As variables relating to the geographical characteristics of the students did not add to the explanatory power of the model they are not presented in Table 3 below but, for completeness, are given in Table 4. Therefore the second block included information relating to students' education before entering higher education. The two variables in this block were also dichotomous. Students were categorised according to whether they had attended a feepaying or state-funded school or college (including comprehensive and grammar schools as well as FE colleges) when they applied to the university and whether they had achieved grades of $\mathrm{AAB}$ or above in their A-levels.

The third and fourth blocks of variables related to the subject studied by each student in higher education. In the third block students were categorised according to the subject group within which the degree subject they studied was classified. The fourth block divided students according to individual degree subjects. As these two blocks contained the same information at different levels of aggregation they were not both included in any single model but, rather, were alternative ways of categorising degree subjects.

Blocks were entered into the models in the chronological order in which they occurred in a students' life in an attempt to differentiate between the relative explanatory power of the different groups of variables. Although the order of entry does not affect the size of the coefficients in a model for any particular set of variables, it is important in terms of gauging 
the contribution a variable, or block of variables, makes to the explanatory power of a model. Because of this, it can have implications for whether variables are retained or removed from a model and affect decisions about whether simpler or more complex models are selected as the best representation of the data. This kind of 'a priori theoretical ordering' is recommended by Cohen and Cohen (1983, p. 124) who argue that it reflects the causal assumptions inherent to this kind of modelling. As such, the models in this study reflected the assumption that some variables can potentially impact of the lives of respondents before others. The variables in the first block, for example, relate to characteristics such as age and ethnicity, which are present from birth. Variables in the second block relate to education and so can only start to impact on respondents after they start school. The third and fourth blocks contain information on subject choice in higher education and so cannot begin to have any influence on outcomes until a respondent has left school. Constructing models in this way means that the explanatory power of variables that are present earlier in respondents' lives can be accounted for before the effects of variables relating to later events are estimated. This goes some way to mitigate against later events serving as invalid proxies for the explanatory power of variables present earlier in respondents' lives.

In the first instance models were constructed using all cases for which relevant data were available. Although the data set included 38,236 respondents, missing data meant that not all of these were included in every model. The effect of missing data is cumulative in multivariate models, so models with more variables invariably included fewer cases. Decisions on the most useful models are informed on one hand by a preference for parsimony and, on the other, by the need to control for theoretically important variables.

The resulting multivariate models are discussed later in the paper. Before examining these in detail, the results of exploratory univariate and bivariate analyses are described directly below.

\section{Subject choice and social characteristics of undergraduates}

Table 1 shows participation rates by subject and subject group for the institution studied. The data represent a summary of all entrants from 1998 to 2006 . The proportion of entrants to each subject and subject group is disaggregated by sex, occupational background, ethnicity, age and geographical origin. For reasons of space, not all subjects and social groups are 
included in this table. Only subjects recruiting more than 40 students per year are included but the figures for the five subject groups include all entrants.

Several features are worth noting, with differences in male and female patterns of subject choice being particularly evident. Female students were a minority among the engineering and physical sciences, making up only $23 \%$ of entrants. They were particularly underrepresented in engineering subjects, with female students comprising only $11 \%$ of mechanical engineering and $12 \%$ of civil engineering students over the period studied. However, women were over-represented in other STEM subjects, and made up 59\% of entrants to the life and environmental sciences. In some subjects, they formed the overwhelming majority; notably in psychology (83\%) and physiotherapy (85\%). The predominance of women in physiotherapy is reflected in the medical and dental sciences subject group as a whole, in which $70 \%$ of entrants were female.

More than two-thirds of students studying subjects in the arts and law subject group were female, as were $57 \%$ of social science entrants. Women made up over three-quarters of students studying English and nearly two-thirds of law students. However, some social science subjects - such as economics and accounting and finance - are clearly maledominated, with women making up only $28 \%$ of economics students and $41 \%$ of those studying accounting and finance.

Simply comparing levels of male and female participation between STEM and non-STEM subjects masks some of the important differences between both subject groups and individual subjects. It is not simply the case that women are under-represented in STEM subjects and over-represented elsewhere, as there are STEM subject groups and subjects that disproportionately recruit female students. Some of these subjects, such as medicine, are predominantly taught in elite institutions. Female students are also over-represented in certain non-STEM subjects such as law. There are, however, some STEM subjects, particularly among those in engineering and the physical sciences, where women continue to be minority participants. This is also the case for key non-STEM subjects such as economics.

Although there were no very large differences in the distribution of students' occupational backgrounds between subject groups, those from higher professional backgrounds were considerably over-represented in the medical and dental sciences and in medicine in particular. Outside of this subject group there was little to suggest that students from higher professional backgrounds were disproportionately drawn to STEM subjects. 
The distribution of students from the main ethnic groups was more noteworthy. Indian and Pakistani students - the two largest minority ethnic groups - made up $7 \%$ and $4 \%$ of all participants, respectively. However, Indian and Pakistani students were over-represented among entrants to the medical and dental sciences in general and to medicine in particular; more than double the expected proportion of students from both these groups enrolled on medical degrees. While participation levels for these groups in the social sciences as a whole were approximately proportionate to their overall participation at this institution, enrolment rates in accounting and finance were much higher, with Indian students making up $23 \%$ of students studying this subject and Pakistani students making up a further 8\%. Indian students were also three times as likely to study accounting than would be expected by their overall rates of participation at this institution.

Non-traditional aged students were slightly over-represented in the medical and dental sciences groups. They were more likely to study vocationally-related subjects such as physiotherapy but almost half as likely to pursue a degree in medicine. They were also less likely than traditional age students to take subjects from the life and environmental sciences or engineering and physical sciences group but were over-represented in the social sciences. Within the social sciences subject group, however, they were extremely under-represented in accounting and finance and particularly in economics.

Subject participation also varied to some extent by students' locality. For example, while the majority of students in each subject group were not local to the university - only $25 \%$ of all students were local - there was some variation between subject groups and individual subjects. The social sciences recruited the lowest proportion of non-local students, at $69 \%$; the life and environmental sciences and arts and law subject groups recruited the highest proportion, at $81 \%$. Sports and exercise science was notable for having the highest proportion of non-local students (90\%) and physiotherapy also had high non-local participation, at $85 \%$. However, in the case of these two subjects this might reflect the position of this institution in the national market rather than indicating any wider pattern. Geography, English and economics also had non-local participation rates over $80 \%$ but so did mechanical engineering, which had a much higher rate than the other subjects in the engineering and physical sciences group. Chemistry and accounting and finance had the highest rates of local entrants, with $39 \%$ of chemistry students having been recruited from the local area and $34 \%$ 
of those students studying accounting and finance also originating locally. There was also some variation in participation rates for students from the different POLAR neighbourhoods. For example, students studying economics, history and psychology tended to come from homes in the highest participation quintiles while those studying chemistry came from areas in the lowest quintiles.

Many of these patterns are not unique to this institution and have been noted in the university application data nationally (e.g. HESA 2014). In addition to reaffirming the persistence of these patterns, they suggest that this case study is likely to be representative of the wider population of students attending 'elite' universities elsewhere in England.

\section{Insert Table 1}

\section{Subject choice, previous qualifications and school sector}

Despite recent increases in the variety and type of post-16 qualifications in the UK, A-levels remained the 'gateway' qualification to this 'elite' university (Table 2). The only notable exceptions to this were social sciences subjects (apart from economics and accounting and finance) which also recruited larger proportions of non-traditional age students. These patterns are likely to be linked, as older entrants are more likely to take Access to HE Diplomas or be admitted on criteria other than traditional academic qualifications. Vocational post-16 qualifications, such as BTECs, are likely to account for at least some of the slightly elevated proportion of non-A-level entrants in the engineering sciences $(15 \%$ in civil engineering, for example) but students gaining entry through qualifications other than Alevels represented only $10 \%$ of those studying engineering and physical science subjects and $12 \%$ of this institution's intake overall.

Almost a quarter of students $(22 \%)$ at this institution were privately educated, compared with around $7 \%$ of the school population and $13 \%$ of A-level candidates nationally (DfE 2013). Students from independent schools were over-represented in the medical and dental sciences, particularly so in medicine (but see footnote about outcomes for medicine degrees at end of Table 2). They were also slightly over-represented in arts, humanities and law subjects. In the biological and environmental sciences and social sciences their participation was proportionate to their overall entry rate but some subjects, such as economics, stand out as 
admitting a larger proportion of independently educated students (29\%) compared to the institution as a whole (22\%).

Examining participation rates within the engineering and physical sciences subject group reveals an interesting anomaly. Privately-educated students were generally under-represented in this subject group, making up only $15 \%$ of students. They were substantially underrepresented among students studying physics, making up only $9 \%$ of the student population, and also in mathematics (11\%), civil engineering (12\%) and chemistry (12\%). Only half the number of privately-educated students studied these subjects than would be expected given their prevalence in the general student population at this institution. However, privatelyeducated students were actually over-represented in mechanical engineering, making up 26\% of undergraduates studying this subject at this institution over the period studied. This is an interesting finding and provides further evidence of the importance of examining participation at the subject-level. However, given the relatively small number of students studying this subject $(\mathrm{n}=439)$, and considering that this represents the combined total of all entrants over a nine year period, this difference should be interpreted with caution. (The number of privately-educated mechanical engineering entrants at this institution averages only just over 12 each year, varying between 2 students in 2006 and 20 students in 1999 and 2000). Nevertheless, this subject does seem to stand out from others in the group and the finding is certainly one worthy of further investigation.

The differences between subjects in the proportion of entrants achieving $\mathrm{ABB}+$ at $\mathrm{A}-\mathrm{level}$ is possibly less interesting because it is likely to reflect the different admissions requirements for these subjects and subject groups. In the multivariate analyses the relationship between social and educational background, A-level attainment and degree classification is investigated in more depth. However, the more basic analysis does show that prior qualifications differ quite considerably across subjects, with $85 \%$ of students arriving with ABB + for English, compared with 19\% for chemistry, for example. Table 2 also shows that a relatively high proportions of students from a number of disciplines (e.g. engineering, biological science and geography) graduate with a 'good' degree despite their lower entry grades.

The descriptive analyses above show the considerable variation in the characteristics of entrants between subjects. While, one-third of history students were privately-educated, only $9 \%$ of physicists came from independent schools. In terms of ethnic background, $96 \%$ of 
geography entrants were white, compared with $75 \%$ across the university. Different patterns of participation for men and women were also evident: $83 \%$ of entrants to study psychology were female; for civil engineering it was $12 \%$. There were also wide variations in entry qualifications, especially between those studying certain arts and science subjects. The relationship between these characteristics and eventual degree success is considered further in the next section.

\section{Insert Table 2}

\section{Student characteristics and academic success}

Table 3 presents the results of four logistic regression models examining the relationship between student characteristics and degree outcomes in different subject areas. The first model includes only the social and occupational backgrounds of students: sex, age, occupational class and ethnicity. The second model adds the educational characteristics discussed earlier. The final two models include subjects studied (as subject groups in Model 3 and individual subjects in Model 4). Locality of students was not included in these models shown because it added little to their explanatory power.

The figures in the table are the odds ratios associated with each variable and represent the increase or decrease in the likelihood of a student achieving a 2:1 or first class grade in their undergraduate degree. A value of exactly one indicates that there is no relationship between the associated variable and degree outcome. Values above one indicate that a characteristic such as being female - is associated with an increased chance of graduating with a 2:1 or first class degree, while values below one indicate that a characteristic is associated with a decreased chance of that outcome. An odds ratio of 1.94 associated with being female, for example, would mean that according to that model female students are nearly twice as likely as male students to graduate with a 2:1 or first class degree (see Table 3, Model 1). An odds ratio of 0.5 would represent the same size effect in the opposite direction (i.e. being half as likely to graduate with a $2: 1$ or higher).

The total number of cases analysed in this model was 27,092. As can be seen in Table 3, because not all respondents provided data in all the relevant fields, the number that can be included in each model decreases with the complexity of the model. In addition in Model 4, 
only students studying the largest subject areas are included and so the dataset is necessarily smaller. Any non-response was unlikely to be random (for example less able students may be more likely to drop out from university) and this needs to be considered when interpreting the findings (more detail on the nature of missing data is provided in note 4 at the end of the paper).

The first model included only the first block of variables, relating to background characteristics. While this model has a relatively small pseudo- $\mathrm{R}^{2}$ of 0.06 it increased the percentages of cases predicted correctly (PCPC) by the model from $68.1 \%$ to $68.5 \%$. According to this model, being white, female, a 'traditional age' entrant and coming from a professional background all increased the chances of graduating with a 2:1 or above.

Model 2 also includes the two variables relating to prior education and further increases the explanatory power of the model. The pseudo- $\mathrm{R}^{2}$ rises to 0.16 and the PCPC to $69.6 \%$. Unsurprisingly, attaining three A-levels at grades ABB or above increases the probability of graduating with a $2: 1$ or above nearly four-fold (odds ratio=3.74). According to this model, having been educated at a state-funded school or college increases the odds of this outcome very slightly but, given the size of this odds ratio (1.14) and the level of unexplained variation in the model, it would be unwise to place too much on this figure. A more cautious conclusion to draw from this finding is that there is no evidence that students educated in independent fee-paying schools are more likely to be successful at this university than their state-educated peers. Once background characteristics and attainment are controlled for, there appears to be no additional value added for privately educated students, at least in terms of undergraduate degree outcomes.

Models 3 and 4 examine whether, once social and educational background is taken into consideration, those studying for particular subjects have a greater chance of graduating with a 'good' degree outcome. It is well-established that the proportion of students graduating with 2:1s or higher varies substantially between degree subjects (Ogg et al. 2009) but the extent to which this is related to variation in the social and educational characteristics of entrants, the nature of the curricula and assessment of particular subjects, or simply the result of differential entry grades, is less clear. These models test the extent to which there is a 'subject effect' in degree outcome once respondents' background characteristics and their prior educational attainment is controlled for. 
Model 3 adds the subject group within which each respondent's degree subject is located. These subject groups correspond approximately to 'faculties' or 'disciplines'. The arts, law and humanities subject group is used as the reference category (because this subject group awarded the highest proportion of 'good' degrees). The first thing to note about this model is that adding the dummy variables relating to subject group does little to increase either the pseudo- $\mathrm{R}^{2}$ or the percentage of cases predicted correctly by the model. The former measure only increases from 0.158 to 0.165 and the latter from $69.6 \%$ to $70.6 \%$. This suggests that the information provided by subject groups does little to help explain any differences in degree outcome. While at least one of the odds ratios suggests a substantial difference between subject groups, the lack of any increase in explanatory power suggests that these variables are merely acting as proxies for variation in the information contained in the first two blocks of variables.

Model 4 does not include subject group data but, instead, includes variables for selected individual degree subjects (with history as the reference category). Focusing only on the largest recruiting subjects does mean that there is a reduction in the number of cases examined. Whereas Model 1 included $71 \%$ of all cases that were available for analysis and Models 2 and 3 included more than 63\%, Model 4 included 9007 cases, or $24 \%$ of the total. Although at first sight this model appears to offer a small increase in explanatory power, given that three-quarters of the possible cases are excluded from the analysis, it would be unwise to place any weight on the estimates produced.

All things considered, Model 2 offers the best compromise between explanatory power and parsimony. Given that none of the models explain more than a minority of the variation in degree outcomes, it is important not to place too much weight on the absolute size of the odds ratios associated with individual characteristics. The model suggests, unsurprisingly, that Alevel results are by far the most important factor in degree outcomes. Identifying as white and being female also seem to be important. The effects associated with being traditional age and professional are considerably smaller and a more cautious interpretation would be that these two groups are not clearly disadvantaged by their status. Given the substantial advantage students from professional and managerial backgrounds have in other phases of education, it is surprising that occupational class appears to play such a small role in perpetuating educational advantage in $\mathrm{HE}$. 


\section{Insert Table $3^{5}$}

\section{Conclusions and implications for policy}

According to a recent report by Feng and Gratz (2013) students who graduate with a 2:1 degree can expect to earn around $7 \%$ more than those who graduate with a $2: 2$. Similar work by Ireland et al. (2009) found that the economic returns for higher degree classifications increased across cohorts during a period of substantial graduate expansion. As more students go to university, achieving a higher degree classification will become increasingly important in terms of economic and labour market returns. Successive surveys by the Association of Graduate Recruiters suggest that the vast majority of graduate recruiters use degree classification as the main benchmark for recruitment (e.g. AGR 2013, 2012). So achieving a $2: 1$ or a $1^{\text {st }}$ class degree is crucial for graduates' early career prospects not merely because of the higher wage premium that is attached to the qualification but simply because it is crucial in helping secure them an interview in the first place.

With this in mind, two key findings emerge from this analysis. First, the subject participation of different social groups is not straightforward and varies considerably between individual subjects. Ethnic, sex and academic differences were particularly evident in a number of subjects, while occupational class differences existed in only a few notable areas. The interaction of these patterns is also important. For example, although sex stereotyped patterns of subject choice were apparent in several STEM subjects (particularly the engineering sciences and physics), these same subjects attracted similar proportions of students from professional occupational backgrounds as arts and humanities subjects (the striking exception to this was medicine).

The second key finding from the research is that attaining a 'good' degree appears to be largely unrelated to the subject a student studies. The data presented here suggests that background and academic characteristics, in particular prior attainment, were the factors mostly closely related to the likelihood of graduating with a 'good' degree. However, unlike in other phases of education, occupational class appeared to be a relatively weak determinant of academic success at university. Additionally, once background characteristics and entry grades had been controlled for, there was little to suggest that being educated in the fee- 
paying independent school sector made any further contribution to the likelihood of attaining a 2:1 or higher.

There is little evidence here to suggest that studying a STEM subject confers any particular advantage on a student in terms of securing a 'good' degree, once characteristics on entry are accounted for. The data offer no support for claims that STEM subjects are academically more challenging than non-STEM subjects and that this level of difficulty might account for any differential degree outcomes. Rather it appears to be the case that differences in degree outcomes between STEM and non-STEM subjects have more to do with students' social background and prior educational attainment than any differences in how grades are awarded at university.

Work by Coe et al. (2008:136) has shown that at A-level, compared to non-STEM subjects, STEM subjects are both 'objectively harder and widely perceived to be so' and the perception that studying science is more difficult than studying arts subjects continues into university (e.g. IET 2008, House of Lords 2012). However the findings from this study provide no evidence to suggest that, when background and prior academic characteristics are taken into account, STEM students are less likely than non-STEM students to graduate with a 'good' degree, despite the perceived difficulty of their programmes.

The models we have been able to produce, however, are limited in the extent to which they can reproduce trajectories into and out of higher education. It could be the case that STEM subjects are more difficult both at A-level and undergraduate-level and that entrants to STEM subjects achieve both lower A-level degrees and degree outcomes simply because they have self-selected STEM subjects throughout their educational careers. This interpretation would mean that Coe et al.'s (2008) findings are not incompatible with those presented here. The historical difference in difficulty between subjects might be explained by the demands of a STEM labour market that requires graduates to have certain knowledge and skills and that requires curricula in schools and universities to reflect this.

Another possible explanation is that any differences between outcomes in STEM and nonSTEM subjects simply reflect the social and academic backgrounds of those studying the different subjects. As both curricula and examinations in schools and universities are subject to external scrutiny and review, it is possible that, the difficulty of assessments is comparable 
between subject areas. This appears at first sight to be a more parsimonious explanation but one that offers little in the way of any obvious solution.

If STEM assessments really are more difficult than those for non-STEM subjects then this problem can be resolved by reviewing these assessments and making the necessary changes. This process might usefully involve a consultation with representatives from the STEMlabour market. Employers may be keen to ensure that STEM graduates have particular knowledge and skills but surely must also be concerned about potentially valuable employees being deterred from studying science because their grades will suffer. This could perhaps change the students' perception of science not only in general terms but in relation to their individual ability in the area.

If, as this paper suggests, differential degree attainment can largely be explained by social background and prior educational attainment, then changing STEM outcomes in HE depends upon widening participation among under-represented groups and attracting higher attaining students. In a context of a long history of school-level initiatives aimed at tackling both these issues, there appear to be no easy answers or obvious solutions.

It must be remembered, however, that concerns about participation and attainment in STEM subjects are driven by a particular discourse, and similar concern is seldom expressed in relation to many other subject areas. While widening participation and raising standards are relatively uncontroversial objectives, a disproportionate amount of attention has been paid to the sciences in relation to these aims. This attention stems from particular views about both the relationship between education and the economy and the contribution that STEM graduates can make in the labour market. More specifically, they are an outcome of particular claims about shortages in the STEM workforce. The extent to which the available evidence supports such a shortage, however, is questionable (Smith and Gorard 2011). If the relative importance of STEM participation and attainment depends on the existence of a shortage, the supply of and demand for STEM graduates needs to be evaluated as a matter of priority.

\section{Notes}

1. The term 'elite universities' is used as shorthand for research-intensive universities who generally (although not exclusively) require the highest entry grades. They tend to comprise 
those institutions that attained university status prior to the 1992 Higher and Further Education Act. The Russell group is a name given to a group of 24 of these institutions.

2. Most universities in the UK use a five point classification for the awarding of undergraduate degrees:

\begin{tabular}{|l|c|c|c|}
\hline $\begin{array}{l}\text { British degree } \\
\text { classification }\end{array}$ & $\begin{array}{c}\text { Marks achieved } \\
(\%)\end{array}$ & $\begin{array}{l}\text { Percentage of awards } \\
\text { nationally }(2009 / 10)^{*}\end{array}$ & $\begin{array}{l}\text { USA Grade Point } \\
\text { Average equivalent }\end{array}$ \\
\hline First & $70+$ & 15 & A (4.00) \\
\hline Upper Second 2(i) & $60-69$ & 51 & A-/B+ (3.33-3.67) \\
\hline Lower Second 2(ii) & $50-59$ & 28 & B (3.00) \\
\hline Third & $40-49$ & 6 & $\mathrm{C}+(2.30)$ \\
\hline Ordinary Pass & $35-40$ & - & $\mathrm{C}(2.00)$ \\
\hline
\end{tabular}

Source: Fulbright Commission (2011)

*Source: HESA (2011). Please note figures are for full-time home domiciled undergraduate students, HESA do not disaggregate awards at Third/Pass

3. This study has adopted an inclusive definition of STEM subjects as used by ISCED (1997) and BIS (2009) that includes the life, health, physical, mathematical and engineering sciences, as well as agriculture and architecture.

4. It is important to note the relatively large amount of missing data in this analysis. Some clarification about the nature of any missing data is given here.

\begin{tabular}{|l|l|l|}
\hline & N & Reason for omission \\
\hline Size of original data set & 38236 & \\
\hline Data set for logistic regression & 24002 & \\
\hline Number of cases missing & 14234 & \\
\hline No final outcome data available & 5388 & $\begin{array}{l}\text { Includes dropout, transfer of university, } \\
\text { death and unknown }\end{array}$ \\
\hline Ethnicity & 2090 & Data not recorded by institution \\
\hline Family occupational class & 3666 & $\begin{array}{l}\text { Data unknown or coded as other by } \\
\text { institution }\end{array}$ \\
\hline A-level grades & 1735 & Non A-level entrant \\
\hline Previous educational institution & 1355 & $\begin{array}{l}\text { Coded as unknown or previous HEI by } \\
\text { institution }\end{array}$ \\
\hline
\end{tabular}

5. The analysis was also run using a technique to maximise the sensitivity of the logistic regression analysis to changes both in the PPC and pseudo r-square values (see: White \& Selwyn 2012, 2013). The results led to the same substantive conclusions and so the more conventional approach to analysis has been presented in Table 3. 


\section{References}

AGR (2012), Graduate starting salaries continue to rise beyond predicted levels, Association of Graduate Recruiters Press Release, July 2012, accessed from www.agr.org.uk/Press -Releases/Graduate-starting-salaries-continue-to-rise-beyond-predictedlevels\#.Ud1xQzusiSo

AGR (2013), Summary of the Association of Graduate Recruiters (AGR) winter survey 2013, University of Leeds Career Service, www.leeds.ac.uk

Barrow, M., Reilly, B., Woodfield, R., (2009): The determinants of undergraduate degree performance: how important is gender?, British Educational Research Journal, 35(4), pp. 575-59.

BBC (2010), Three quarters of employers 'require 2:1 degree', BBC online, $6^{\text {th }}$ July 2010 , http://news.bbc.co.uk/1/hi/education/10506798.stm

BIS (2009), The Demand for Science, Technology, Engineering and Mathematics (STEM)

Skills, Department for Innovation, Universities and Skills, accessed March 2010 http://www.bis.gov.uk/ assets/ biscore/corporate/migratedd/publications/d/ demand_ for_stem_skills.pdf

Boliver, V., (2013), How fair is access to more prestigious UK universities? The British Journal of Sociology, 64(2), pp. 344-364

Ceci, S., Williams, W. and Barnett, S. (2009) Women's underrepresentation in science: sociocultural and biological considerations, Psychological Bulletin, 135 (2), 218-261.

Chevalier, A., (2000), Graduate Over-Education in the UK, Centre for the Economics of Education Discussion Paper 7, London School of Economics.

Chowdry, H., Crawford, C., Dearden, L., Goodman, A. and Vignoles, A. (2010) Widening Participation in Higher Education: Analysis Using Linked Administrative Data. London: IFS/ESRC, accessed from: http://www.ifs.org.uk/wps/wp1004.pdf.

Coe, R., Searle, J., Barmby, P., Jones, K., Higgins, S., (2008), Relative difficulty of examinations in different subjects, Report for SCORE, accessed May 2009

Cohen, J. \& Cohen, P. (1983) Applied Multiple Regression/Correlation Analysis for the Behavioural Sciences, 2nd edn, Erlbaum, Hillsdale, NJ.

Department for Children, Schools and Families (2006) The Science, Technology, Engineering, and Mathematics Programme Report, Accessed from www.dcsf.gov.uk/hegateway/uploads/STEM\%20Programme\%20Report.pdf.

Department for Education (2013), Schools, pupils and their characteristics: January 2013, SFR21/2013, London: Department for Education.

Dolton, P., Silles, M., (2003), The Determinants and Consequences of Graduate Overeducation, in Buchel, F., de Grip A., Mertens, A., (Eds), Over-education in Europe: Current Issues in Theory and Policy, Cheltenham: Edward Elgar.

Elias, P., Purcell, K., (2004), Researching Graduate Careers Seven Years On, SOC (HE): A classification of occupations for studying the graduate labour market, Research paper No. 6, Warwick Institute for Employment Research, accessed from www2.warwick.ac.uk/fac/soc/ier/research/completed/7yrs2/rp6.pdf

Feng, A., Graetz, G., (2013), University exam results matter, CenterPiece, Summer 2013, accessed from http://cep.lse.ac.uk/pubs/download/cp395.pdf 
Furlong, A. and Cartmel, F. (2009) Higher Education and Social Justice. Buckingham: Open University Press.

Gorard, S., (2003), 'Understanding Probabilities and Re-Considering Traditional Research Training', Sociological Research Online, 8:1.

Gorard, S. (2008). 'Who is missing from higher education?' Cambridge Journal of Education, 38(3), pp. 421-437.

Gorard, S. (2010). 'All evidence is equal: the flaw in statistical reasoning', Oxford Review of Education, 36(1), pp. 63-67.

Gorard, S. (2014) 'The widespread abuse of statistics by researchers: What is the problem and what is the ethical way forward?', The Psychology of Education Review, 38(1), pp. 3-11.

Gorard, S., Adnett, N., May, H., Slack, K., Smith, E., Thomas, L., (2007), Overcoming the barriers to higher education, Stoke-on-Trent: Trentham Books.

Green, F., Zhu, Y., (2010), Overqualification, job dissatisfaction, and increasing dispersion in the returns to graduate education, Oxford Economic Papers 62, pp740-763

Guardian (2012), Most graduate recruiters now looking for at least a 2:1, $4^{\text {th }}$ July 2012 , accessed from http://www.guardian.co.uk/money/2012/jul/04/graduate-recruiterslook-for-21-degree

Harrison, N., Hatt, S., (2009), Knowing the 'unknowns': Investigating the students whose social class is not known at entry to higher education. Journal of Further and Higher Education 33, no. 4: 347-57.

HESA (2014), Higher Education student enrolments and qualifications obtained at Higher Education Institutions in the United Kingdom for the academic year 2012/13, SFR 197, Cheltenham: HESA.

House of Lords (2012), Higher Education in Science, Technology, Engineering and Mathematics (STEM) subjects report, Select Committee on Science and Technology, London: The Stationery Office Limited

IET (2008), Studying STEM: what are the barriers? A literature review of the choices students make, Institution of Engineering and Technology.

Independent Reviewer on Social Mobility and Child Poverty (2012), University Challenge: How Higher Education Can Advance Social Mobility, London: Cabinet Office

Ireland, N., Naylor, R.A., Smith, J., Telhaj, S., (2009), Educational Returns, ability composition and cohort effects: theory and evidence for cohorts of early-career UK graduates, Warwick Economic Research Papers No. 906, accessed from http://wrap.warwick.ac.uk/1311/1/WRAP_ireland_twerp_906.pdf

Jenkins, E.W., Donnelly, J.F., (2006), Educational reform and the take-up of science post-16, paper presented at the Royal Society conference 'Increasing the take-up of science post-16' March $16^{\text {th }} 2006$.

Mangan, J., Hughes, A., Davies, P. and Slack, K. (2010) 'Fair access, achievement and geography: explaining the association between social class and students' choice of university', Studies in Higher Education, 35 (3): 335-50.

McNabb, R., Sarmistha, P., Sloane P., (2002), Gender differences in students attainment: the case of university students in the UK, Economica, 69, pp481-503.

Naylor R.A., Smith, J., (2004), Determinants of educational success in higher education, in 
the International Handbook on the Economics of Education, in Johnes, G and Johnes J., Eds, Cheltenham: Edward Elgar Publishing Limited

OFFA (2010), What more can be done to widen access to highly selective universities?, Office for Fair Access, April 2010, accessed from http://www.offa.org.uk/wpcontent/uploads/2010/05/Report-on-access-to-highly-selective-universities.pdf

OFFA (2014), Office For Fair Access: Access agreements, accessed May 2014 from http://www.offa.org.uk/access-agreements/

Ogg, T., Zimdars, A., Heath, A., (2009) 'Schooling effects on degree performance: a comparison of the predictive validity of aptitude testing and secondary school grades at Oxford University', British Educational Research Journal, 35(5), pp781-807.

Prentice, R.L., and R. Pyke. 1979. 'Logistic disease incidence models and case-control studies'. Biometrika, 66 (3), pp. 403-11.

Purcell, K., Elias, P., Wilton, N., (2006), Looking through the glass ceiling: a detailed investigation of the factors that contribute to gendered career inequalities, Warwick Institute for Employment Research, accessed from http://www2.warwick.ac.uk/fac/soc/ier/research/completed/ltgc/esfreportfinal.pdf

Reay, D., David, M. and Ball, S. (2005) Degrees of Choice: Social Class, Race, Gender in Higher Education. Stoke-on-Trent: Trentham Books.

Richardson, J.T.E., Woodley, A., (2003), Another Look at the Role of Age, Gender and Subject as Predictors of Academic Attainment in Higher Education, Studies in Higher Education, 28(4), pp475-493.

Seaton, N., (2011), Degree classification is unfair to many students, The Guardian, $18^{\text {th }}$ April 2011, http://www.guardian.co.uk/education/2011/apr/18/higher-education-degreeclassification?INTCMP=ILCNETTXT3487

Smith, E., (2010), Do we need more scientists? A long term view of patterns of participation in UK Undergraduate Science Programmes, Cambridge Journal of Education, 40(3), pp281-298.

Smith, E., Gorard, S. (2011) Is there a shortage of scientists? A re-analysis of supply for the UK, British Journal of Educational Studies, 59(2), 159-177

Smith, J., Naylor, R.A (2001), Determinants of individual degree performance: evidence for the 1993 UK university graduate population from the USR, Oxford Bulletin of Economics and Statistics, 63, pp29-60.

Social Mobility and Child Poverty Commission (2013), Higher Education: the Fair Access Challenge, London: Social Mobility and Child Poverty Commission

Surtees, P. G., Wainwright, N. W. J., Pharoah, P. D. P. (2002), Psychosocial factors and sex differences in high academic attainment at Cambridge University, Oxford Review of Education, 28(1), pp21-38.

The Sutton Trust (2008), Increasing higher education participation amongst disadvantaged young people and schools in poor communities, London: The Sutton Trust.

White, P. (2014), Against inferential statistics, The Psychology of Education Review, 38(1),2 pp24-28.

White, P. and Selwyn, N. (2013) 'Moving online? An analysis of patterns of adult internet use in the UK, 2002 to 2010', Information, Communication and Society, 16 (1), pp. 127.

White, P. and Selwyn, N. (2012) 'Learning online? Educational internet use and participation in adult learning, 2002 to 2010', Educational Review, 64 (4), pp. 451-469. 
Woodfield, R., Earl-Novell, S., (2006), An assessment of the extent to which subject variation between the arts and sciences in relation to the award of a first class degree can explain the 'gender gap' in UK Universities, British Journal of Sociology of Education, 27(3), pp355-372

Wynarczyk, P., Hale, S., (2009), Improving Take up of Science and Technology Subjects in Schools and Colleges: A Synthesis Review Report prepared for the Economic and Social Research Council "Science in Society" Team and the DCSF, accessed September 2010 from http://tinyurl.com/39xqo8o 
Table 1: Selected background characteristics for 1998-2006 cohorts, main subject groups and highest recruiting subjects only

\begin{tabular}{|c|c|c|c|c|c|c|c|c|c|c|c|c|c|c|c|}
\hline & \multirow[t]{2}{*}{$\mathrm{N}$} & \multirow[t]{2}{*}{$\begin{array}{c}\text { Female } \\
(\%)\end{array}$} & \multirow{2}{*}{$\begin{array}{c}\text { Higher } \\
\text { Prof. } \\
(\%)\end{array}$} & \multirow{2}{*}{$\begin{array}{c}\text { Lower } \\
\text { Prof. } \\
(\%)\end{array}$} & \multirow{2}{*}{$\begin{array}{l}\text { Inter- } \\
\text { 'dte } \\
(\%)\end{array}$} & \multirow[t]{2}{*}{$\begin{array}{c}\text { Routine } \\
(\%)\end{array}$} & \multirow[t]{2}{*}{$\begin{array}{l}\text { White } \\
(\%)\end{array}$} & \multirow[t]{2}{*}{$\begin{array}{c}\text { Indian } \\
(\%)\end{array}$} & \multirow[t]{2}{*}{$\begin{array}{c}\text { Pakistani } \\
(\%)\end{array}$} & \multirow{2}{*}{$\begin{array}{l}\text { Age } \\
21+ \\
(\%)\end{array}$} & \multirow{2}{*}{$\begin{array}{c}\text { Not } \\
\text { local } \\
(\%)\end{array}$} & \multicolumn{2}{|c|}{$\begin{array}{c}\text { Adult HE } \\
\text { qualific'n quintile }\end{array}$} & \multicolumn{2}{|c|}{$\begin{array}{l}\text { Young P'pn } \\
\text { quintile (\%) }\end{array}$} \\
\hline & & & & & & & & & & & & Highest & Lowest & Highest & Lowest \\
\hline Medical \& Dental Sci & 4687 & 70 & 30 & 30 & 17 & 10 & 65 & 14 & 7 & 13 & 72 & 29 & 11 & 39 & 6 \\
\hline Physiotherapy & 680 & 85 & 26 & 33 & 21 & 8 & 92 & 1 & 1 & 18 & 85 & 34 & 6 & 48 & 4 \\
\hline Medicine & 1803 & 59 & 38 & 31 & 15 & 7 & 62 & 17 & 9 & 6 & & 32 & 8 & 42 & 6 \\
\hline Life/Environmental Sci & 7809 & & & & & & & & & & & & & & \\
\hline Biological Science & 653 & & & & & & & & & & & & & & \\
\hline & & 02 & 24 & 35 & 20 & 11 & 18 & f & 4 & 2 & 14 & & 12 & & 7 \\
\hline Psychology & 1275 & 83 & 26 & 35 & 18 & 11 & 81 & 5 & 2 & 4 & 78 & 37 & 9 & 43 & 6 \\
\hline Sports \& Exercise Sci & 1251 & 53 & 23 & 40 & 19 & 9 & 92 & 1 & 0.2 & 3 & 90 & 30 & 8 & 39 & 5 \\
\hline Geography & 1525 & 54 & 30 & 37 & 19 & 8 & 96 & 1 & 0.3 & 1 & 88 & 34 & 6 & 45 & 4 \\
\hline & & & & & & & & & & & & & & & \\
\hline Engineering \& Phys. Sci. & 6613 & 23 & 21 & 32 & 20 & 14 & 70 & 9 & 4 & 6 & 72 & 24 & 13 & 33 & 9 \\
\hline Chemistry & 421 & 36 & 16 & 31 & 23 & 14 & 69 & 11 & 8 & 4 & 61 & 19 & 19 & 24 & 10 \\
\hline Civil Engineering & 256 & 12 & 22 & 25 & 20 & 15 & 74 & 6 & 6 & 8 & 72 & 26 & 11 & 33 & 11 \\
\hline Mathematics & 754 & 43 & 21 & 34 & 20 & 15 & 78 & 9 & 2 & 3 & 74 & 21 & 12 & 32 & 9 \\
\hline Mechanical Engineering & 439 & 11 & 23 & 33 & 22 & 12 & 89 & 3 & 2 & 5 & 84 & 28 & 7 & 43 & 6 \\
\hline Physics & 298 & 18 & 23 & 33 & 25 & 11 & 81 & 7 & 4 & 3 & 75 & 23 & 16 & 31 & 10 \\
\hline Arts and Law & 10601 & 67 & 25 & 37 & 17 & 9 & 83 & 3 & 2 & 7 & 81 & 35 & 9 & 43 & 6 \\
\hline Law & 1393 & 64 & 24 & 35 & 17 & 12 & 71 & 11 & 5 & 5 & 73 & 29 & 13 & 40 & 7 \\
\hline English & 1022 & 76 & 27 & 36 & 17 & 11 & 88 & 3 & 1 & 8 & 81 & 33 & 9 & 42 & 6 \\
\hline History & 886 & 51 & 29 & 35 & 19 & 9 & 93 & 1 & 1 & 3 & 86 & 37 & 5 & 45 & 4 \\
\hline Social Sciences & 8526 & 57 & 18 & 29 & 15 & 11 & 66 & 8 & 4 & 20 & 69 & 30 & 13 & 37 & 9 \\
\hline Economics & 676 & 28 & 25 & 35 & 18 & 14 & 62 & 21 & 3 & 1 & 86 & 37 & 6 & 47 & 4 \\
\hline Accounting \& Finance & 633 & 41 & 19 & 30 & 23 & 18 & 57 & 23 & 8 & 3 & 66 & 23 & 13 & 34 & 7 \\
\hline All subjects & 38263 & 56 & 23 & 33 & 17 & 11 & 75 & 7 & 4 & 10 & 75 & 30 & 11 & 39 & 7 \\
\hline
\end{tabular}


Table 2: Academic qualifications and education sector, highest recruiting subjects, all years

\begin{tabular}{|c|c|c|c|c|c|c|c|}
\hline Subject & $\begin{array}{c}\text { Total } \\
(\mathrm{N})\end{array}$ & $\begin{array}{c}\text { Non A- } \\
\text { level entry } \\
(\%)\end{array}$ & $\begin{array}{l}\text { Independent } \\
\text { school }(\%)\end{array}$ & $\begin{array}{c}\text { Grammar } \\
\text { school }(\%)\end{array}$ & $\begin{array}{c}\text { Comprehensive } \\
\text { school }(\%)\end{array}$ & $\begin{array}{c}\mathrm{ABB}+ \\
(\%)\end{array}$ & $\begin{array}{c}1^{\mathrm{st}} / 2(\mathrm{i}) \\
(\%)\end{array}$ \\
\hline Medical and dental sciences & 4687 & 9 & 26 & 16 & 45 & 65 & 67 \\
\hline Physiotherapy & 680 & 9 & 21 & 12 & 53 & 69 & 77 \\
\hline Medicine* & 1803 & 4 & 35 & 20 & 38 & 93 & $\mathrm{~N} / \mathrm{A}$ \\
\hline Life \& environmental sciences & 7809 & 6 & 20 & 12 & 58 & 36 & 66 \\
\hline Biological Science & 653 & 6 & 18 & 13 & 59 & 23 & 53 \\
\hline Psychology & 1275 & 6 & 22 & 12 & 54 & 65 & 82 \\
\hline Sports and Exercise science & 1251 & 8 & 18 & 10 & 62 & 45 & 76 \\
\hline Geography & 1525 & 4 & 28 & 14 & 52 & 37 & 74 \\
\hline Engineering \& physical sciences & 6613 & 10 & 14 & 13 & 60 & 29 & 53 \\
\hline Chemistry & 421 & 6 & 12 & 12 & 66 & 19 & 46 \\
\hline Civil Engineering & 256 & 15 & 12 & 11 & 66 & 20 & 55 \\
\hline Mathematics & 754 & 4 & 11 & 13 & 67 & 48 & 50 \\
\hline Mechanical Engineering & 439 & 12 & 25 & 11 & 54 & 24 & 59 \\
\hline Physics & 298 & 5 & 9 & 11 & 70 & 31 & 42 \\
\hline Arts, humanities and law & 10601 & 9 & 26 & 14 & 49 & 59 & 73 \\
\hline Law & 1393 & 7 & 23 & 14 & 50 & 79 & 64 \\
\hline English & 1022 & 8 & 25 & 14 & 50 & 85 & 81 \\
\hline History & 886 & 5 & 32 & 15 & 47 & 80 & 84 \\
\hline Social sciences & 8526 & 24 & 20 & 11 & 49 & 32 & 66 \\
\hline Economics & 676 & 3 & 29 & 18 & 47 & 52 & 70 \\
\hline Accounting and Finance & 633 & 4 & 20 & 13 & 58 & 40 & 62 \\
\hline All students & 32848 & 12 & 22 & 13 & 52 & 44 & 66 \\
\hline
\end{tabular}

*In the UK Medicine degrees are awarded using different methods of classification to other degrees. Therefore our consideration of Medical students is limited to patterns of participation rather than outcomes. 
Table 3: Odds ratios for logistic regression model of degree outcome, all cohorts

\begin{tabular}{|c|c|c|c|c|}
\hline \multicolumn{5}{|c|}{ All students - likelihood of achieving 2(i) or $1^{\text {st }}$ class degree } \\
\hline & Model 1 & Model 2 & Model 3 & Model 4 \\
\hline \multicolumn{5}{|l|}{ Background characteristics } \\
\hline Female & 1.94 & 1.77 & 1.69 & 1.75 \\
\hline Traditional age & 1.20 & 1.05 & 1.08 & 1.26 \\
\hline Professional & 1.20 & 1.16 & 1.16 & 1.10 \\
\hline White & 2.02 & 1.90 & 1.91 & 1.60 \\
\hline \multicolumn{5}{|l|}{ Academic characteristics } \\
\hline State educated & & 1.14 & 1.17 & 1.30 \\
\hline A-levels ABB + & & 3.74 & 3.75 & 3.42 \\
\hline \multicolumn{5}{|c|}{ Subject groups (reference Arts, Law and Humanities) } \\
\hline Social Sciences & & & 1.31 & \\
\hline Engineering \& physical sci. & & & 0.71 & \\
\hline Biological sciences & & & 0.93 & \\
\hline Medical sciences & & & 0.88 & \\
\hline \multicolumn{5}{|l|}{ Subjects (reference History) } \\
\hline Physics & & & & 0.26 \\
\hline Civil Engineering & & & & 0.75 \\
\hline Law & & & & 0.36 \\
\hline Psychology & & & & 0.94 \\
\hline Sport and exercise science & & & & 0.96 \\
\hline English & & & & 0.72 \\
\hline Physiotherapy & & & & 0.65 \\
\hline Economics & & & & 0.80 \\
\hline Biological sciences & & & & 0.40 \\
\hline Accounting & & & & 0.59 \\
\hline Mechanical Engineering & & & & 0.70 \\
\hline Chemistry & & & & 0.37 \\
\hline Maths & & & & 0.29 \\
\hline Geography & & & & 0.84 \\
\hline $\mathrm{N}$ & 27092 & 24002 & 24002 & 9007 \\
\hline & & & & \\
\hline $\begin{array}{l}\% \text { predicted correctly ( } 68.1 \\
\text { base) }\end{array}$ & 68.5 & 69.6 & 70.6 & 73.9 \\
\hline Nagelkerke pseudo- $\mathrm{R}^{2}$ & 0.057 & 0.158 & 0.165 & 0.193 \\
\hline
\end{tabular}




\section{Appendix}

For clarity and reasons of space, we include Table 4 in the appendix rather than in the main body of the paper. It shows all the variables that were available for analysis and the extent to which they contribute to the explanatory power of the model. This provides the justification for why certain decisions were made during the data analysis process to collapse certain variables (such as age and ethnic group) and to remove others (such as year of entry and geographical characteristics) from the final, most parsimonious model.

Because this analysis is based on data taken from the whole population of home domiciled undergraduate students at this institution, tests of statistical significance are not helpful. These figures were requested by one reviewer, however, and we are happy to provide them to readers on request.

Table 4: Odds ratios for logistic regression model of degree outcome, all variables

\begin{tabular}{|c|c|c|c|c|c|}
\hline & Model 1 & Model 2 & Model 3 & Model 4 & Model 5 \\
\hline \multicolumn{6}{|l|}{ Background characteristics } \\
\hline Female & 1.91 & 1.92 & 1.78 & 1.71 & 1.78 \\
\hline \multicolumn{6}{|l|}{ Ethnicity (Reference white) } \\
\hline Bangladeshi & 0.39 & 0.49 & 0.51 & 0.51 & 0.51 \\
\hline Chinese & 0.42 & 0.41 & 0.45 & 0.46 & 0.57 \\
\hline Indian & 0.51 & 0.56 & 0.60 & 0.59 & 0.66 \\
\hline Asian (other) & 0.44 & 0.46 & 0.46 & 0.47 & 0.48 \\
\hline Pakistani & 0.36 & 0.44 & 0.50 & 0.49 & 0.70 \\
\hline Black (African) & 0.45 & 0.44 & 0.56 & 0.56 & 0.41 \\
\hline Black(Caribbean) & 0.37 & 0.42 & 0.55 & 0.54 & 0.59 \\
\hline Mixed Race & 0.85 & 0.87 & 0.88 & 0.88 & 0.91 \\
\hline Other & 0.46 & 0.48 & 0.54 & 0.53 & 0.51 \\
\hline \multicolumn{6}{|c|}{ Occupational class (Reference Higher Prof) } \\
\hline Lower Professional & 0.90 & 0.93 & 0.95 & 0.93 & 0.94 \\
\hline Intermediate & 0.83 & 0.88 & 0.91 & 0.91 & 0.92 \\
\hline Routine & 0.69 & 0.78 & 0.85 & 0.84 & 0.90 \\
\hline \multicolumn{6}{|c|}{ Age group (Reference 17-18) } \\
\hline 19 & 1.09 & 1.07 & 1.11 & 1.10 & 1.08 \\
\hline 20 & 0.97 & 0.98 & 1.05 & 1.04 & 0.96 \\
\hline $21-24$ & 0.69 & 0.73 & 1.04 & 1.02 & 0.96 \\
\hline $25-34$ & 0.52 & 0.59 & 1.23 & 1.28 & 1.04 \\
\hline $35+$ & 0.65 & 0.78 & 7.89 & 7.59 & 1.54 \\
\hline \multicolumn{6}{|c|}{\begin{tabular}{|l|} 
Geographical characteristics \\
\end{tabular}} \\
\hline Local & & 0.73 & 0.76 & 0.76 & 0.93 \\
\hline \multicolumn{6}{|c|}{ Young participation quintile (Reference highest quintile) } \\
\hline Second quintile & & 0.98 & 1.03 & 1.03 & 1.17 \\
\hline Third quintile & & 0.95 & 0.98 & 0.97 & 0.88 \\
\hline Fourth quintile & & 0.95 & 0.93 & 0.93 & 0.85 \\
\hline Lowest (fifth) quintile & & 1.02 & 1.00 & 1.00 & 0.95 \\
\hline \multicolumn{6}{|c|}{ Adult HE qualification (Reference highest quintile) } \\
\hline Second quintile & & 0.81 & 0.84 & 0.87 & 0.86 \\
\hline Third quintile & & 0.92 & 0.92 & 0.94 & 1.00 \\
\hline Fourth quintile & & 0.88 & 0.94 & 0.96 & 1.02 \\
\hline Lowest (fifth) quintile & & 0.97 & 1.01 & 1.02 & 0.99 \\
\hline \multicolumn{6}{|l|}{ Academic characteristics } \\
\hline \multicolumn{6}{|c|}{ School type (Reference Comprehensive) } \\
\hline FE other colleges & & & 0.80 & 0.79 & 0.75 \\
\hline Grammar & & & 1.05 & 1.04 & 1.14 \\
\hline Independent & & & 0.79 & 0.77 & 0.72 \\
\hline
\end{tabular}




\begin{tabular}{|c|c|c|c|c|c|}
\hline $\mathrm{ABB}+$ on entry & & & 3.68 & 3.71 & 3.38 \\
\hline \multicolumn{6}{|l|}{ Year of entry (reference 2006) } \\
\hline 1998 & & & 1.03 & 1.09 & 1.07 \\
\hline 1999 & & & 0.96 & 1.01 & 0.96 \\
\hline 2000 & & & 0.94 & 0.98 & 0.88 \\
\hline 2001 & & & 1.07 & 1.10 & 1.11 \\
\hline 2002 & & & 0.96 & 0.98 & 0.84 \\
\hline 2003 & & & 0.96 & 0.97 & 0.93 \\
\hline 2004 & & & 0.90 & 0.91 & 0.99 \\
\hline 2005 & & & 1.13 & 1.14 & 1.35 \\
\hline \multicolumn{6}{|c|}{ Subject groups (Reference Arts, Humanities and Law) } \\
\hline Social Sciences & & & & 1.33 & \\
\hline Engineering and Physical science & & & & 0.80 & \\
\hline Biological science & & & & 0.93 & \\
\hline Medical science* & & & & 0.90 & \\
\hline \multicolumn{6}{|l|}{ Subjects (Reference History) } \\
\hline Physics & & & & & 0.27 \\
\hline Civil Engineering & & & & & 0.73 \\
\hline Law & & & & & 0.37 \\
\hline Psychology & & & & & 0.94 \\
\hline Sport and exercise science & & & & & 0.95 \\
\hline English & & & & & 0.74 \\
\hline Physiotherapy & & & & & 0.64 \\
\hline Economics & & & & & 0.80 \\
\hline Biological sciences & & & & & 0.41 \\
\hline Accounting & & & & & 0.60 \\
\hline Mechanical Engineering & & & & & 0.70 \\
\hline Chemistry & & & & & 0.39 \\
\hline Maths & & & & & 0.29 \\
\hline Geography & & & & & 0.85 \\
\hline$\%$ cases predicted correctly (baseline $=67.6 \%$ ) & 68.5 & 68.3 & 70.6 & 71.2 & 74.3 \\
\hline $\mathrm{N}$ & 27038 & 26703 & 23659 & 23659 & 8894 \\
\hline Nagelkerke pseudo- $\mathrm{R}^{2}$ & 0.069 & 0.076 & 0.168 & 0.175 & 0.203 \\
\hline
\end{tabular}

*Excluding students whose degree in is medicine 